\title{
The effect of a traditional and a stick gang-line on the body position of working sled dogs
}

\author{
F. Pittet ${ }^{1}$, C.M. McGowan ${ }^{1}$ and H.K. Hyytiäinen ${ }^{2 *}$ \\ ${ }^{1}$ School of Veterinary Science, University of Liverpool, Leahurst Campus, Chester High Road, Neston, Wirral, CH64 7TE, United Kingdom; \\ 2Department of Equine and Small Animal Medicine, Faculty of Veterinary Medicine, University of Helsinki, P.O. Box 57, Helsinki, 00014, \\ Finland; heli.hyytiainen@helsinki.fi
}

Received: 11 June 2020 / Accepted: 8 September 2020

2021 Wageningen Academic Publishers

OPEN ACCESS (C) (1) (-) (2)

RESEARCH ARTICLE

\begin{abstract}
This study aimed to investigate the effect of two different gang-lines on the pulling angle of sled dogs. It was hypothesised that dogs would run with a straighter angle of pull (in relation to the main-line) in stick gang-lines (STICK) than they would do in traditional gang-lines (TRAD). Eight sled dogs, divided into two teams, ran a 3.1 $\mathrm{km}$ trail twice in both types of gang-lines, pulling a quadbike on dry ground. Each dog remained in its team in the same position (side of gang line, and forward or back in the line) for both runs, using both types of lines in randomised order between the runs. Markers were placed on the dogs and on the main lines, and the runs were recorded by a video camera. The dogs' angle of pull measured from the video recordings was compared between the two conditions. Thirteen positional measurements for each dog during each run were taken. The dogs were used to running in TRAD and were not acclimatised to STICK. Data was analysed using Wilcoxon and Spearmans rho tests. Data regarding individual dogs $(n=13)$, teams $(n=52)$, dogs' placements in teams $(n=4)$, and gang-line related pulling angles $(\mathrm{n}=104)$ was analysed. Overall, the position of the dogs was straighter when pulling in STICK, than when pulling in TRAD, with a median of $19^{\circ}$ (inter quartile range (IQR) $24.75^{\circ}$ ) and $32^{\circ}$ (IQR $25.75^{\circ}$ ), respectively $(P<0.001)$. Between the two teams, there was no significant difference in pulling positions when running in STICK $(P=0.543)$, but there was in TRAD $(P<0.001)$. In individual assessment, six of the eight dogs ran in a straighter position ( $P=0.003$ to 0.046$)$ in STICK. Dogs running in the front of both teams pulled significantly straighter when in STICK $\left(21^{\circ}\right.$; IQR 23.75) than in TRAD (median $39^{\circ}$; IQR $\left.18 ; P<0.001\right)$.
\end{abstract}

Keywords: pulling position, kinematic, dog welfare

\section{Introduction}

Sled dogs pull for several hours and several hundreds of kilometres at a time. For example, in USA, the Yukon Quest and the Iditarod competitions, dogs run 1,600 km over 8 to 14 days (Iditarod, 2018, Yukon Quest, 2018a), and in North Europe, the $600 \mathrm{~km}$ Femundlopet race, and the 1,200 km Finnmarkslope race, are run over 5 to 6 days (Femundlopet, 2018; Finnamrkslopet, 2018). In Husky farms, dogs run between 30 to $60 \mathrm{~km} \mathrm{/} 3$ to $6 \mathrm{~h}$ per day (Hetta Huskies, 2018; Wilderness Tour, 2018). The dogs are placed in a team, pulling a sled during winter (LaBelle, 2007a), or a cart, quadbike or bicycle during non-snow seasons (Carter and Hall, 2018).
All dogs are attached by a line called the 'gang-line'. The gang-line is traditionally a rope line; composed of a mainline (or tow-line), some tug-lines between the main-line and the harnesses of the dogs, some neck lines between the main-line, and finally the collar of the dogs (Figure 1A) (Grandjean, 1989; LaBelle, 2007b). A damper may be used between the sled or cycle and the main-line to absorb shocks (LaBelle, 2007b). An alternative version to the above described traditional one, has a rigid stick between the main-line and the tug-line, running perpendicularly to the main line, attaching to the tug line approximately midway along the tug line, affecting the angle of pull of the line in relation to the dog (Figure 1B). Anecdotally it is assumed, that dogs run straighter in the stick gang-lines, as the sticks change the orientation of the pull. 

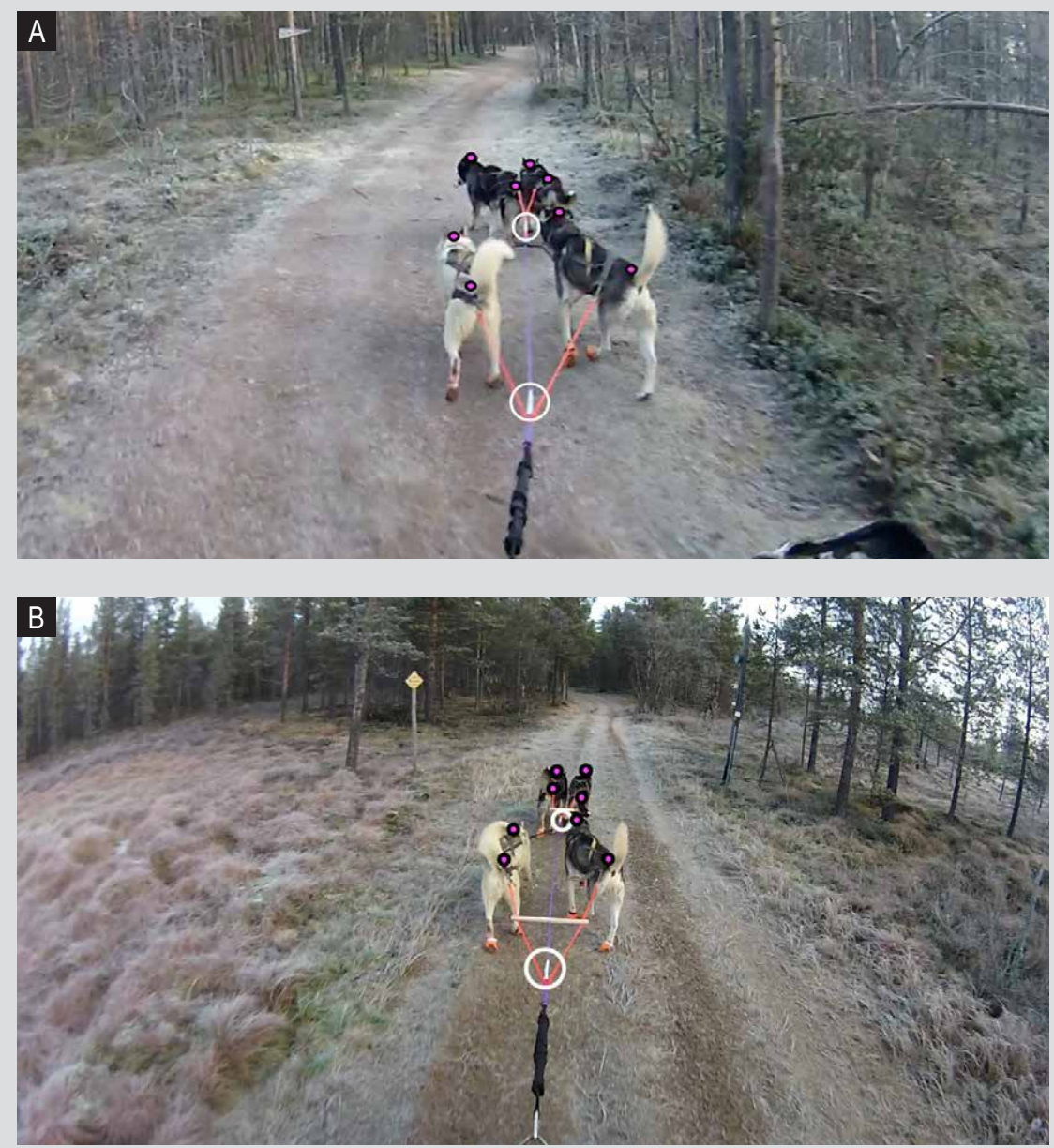

Figure 1. Gang-lines and dogs with markers highlighted. In the middle, the mainline is shown and in a different colour, the tug-lines attached to the dogs. The main line reflective markers circled in white, and dogs' markers emphasised with small black circles. (A) The traditional gang-line set up; (B) the stick gang-line; (C) the colour marks on a dog.

The dogs' work effort is related to the angle of pull. The angle of traction changes the amount of force needed to pull. The more parallel to the direction of the pull the line is, the less force is required to pull. As an example, to open a door with a rope, a dog needs to pull with $44.5 \mathrm{~N}$ if the rope is perpendicular to the door (i.e. 90 degrees angle to the door). The force demand rises to $97.9 \mathrm{~N}$ if the rope is at a $60^{\circ}$ angle to the door (Coppinger et al., 1998). In a study where a handler sitting in a wheelchair held the tow strap at the side of the wheelchair and instructed a dog to pull, the dog was actually observed to pull in a sideways direction, even though the dog was parallel to the direction of movement (Coppinger et al., 1998).

As well as work effort, research has shown that a side load influences the gait biomechanics and increases the thoracic and pelvic rotation in humans (Gysin et al., 2008; Orantes-Gonzalez and Heredia-Jimenez, 2017). This type of torsion of the body can lead to musculoskeletal strain and dysfunction (Orantes-Gonzalez and Heredia-

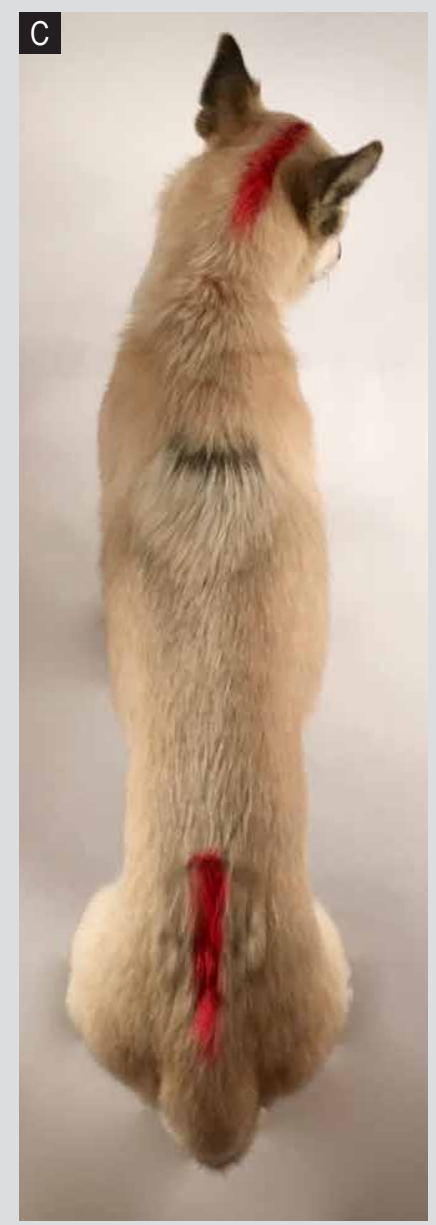

Jimenez, 2017; Ortega et al., 2014). If this is the case with a biped, it can be assumed that the effect of an uneven load distribution during pulling could influence the development of musculoskeletal strain or dysfunction during quadruped work too. In a report of sled dog's injuries during races, $38.3 \%$ (330) of the studied dogs were withdrawn from the race; 50.6\% (167) of these with orthopaedic injuries (Von Pfeil et al., 2015). The most common sites of orthopaedic injuries were shoulder (biceps, triceps, pectoralis; 30.6\%), carpus $(12.7 \%)$, pelvic and limb injuries (metatarsus, tarsus, coxofemoral joint, femur, stifle; $4.5 \%$ ), and muscle and tendon problems in the pelvic limb (Achilles tendon, hamstrings, gastrocnemius, quadriceps; 2.8\%) (Von Pfeil et al., 2015).

Despite sled dogs being working dogs, there is a dearth of information as to the mechanism of pulling (Peham et al., 2013), and effect of various equipment on the performance and welfare of these animals. This study aims to look into the effect of two different gang-lines on the pulling angles 
of the sled dogs, and if the pulling angles are straighter with stick gang-lines than in traditional ones. We hypothesise, that dogs will run with a straighter pulling angle in relation to the main-line, when in stick gang-lines, than when pulling in the traditional ones. If the hypothesis is accepted, the results could help sled dog owners improve animal welfare by prevention of musculoskeletal disease through informed equipment selection.

\section{Materials and methods}

The study was a prospective cross-over study. It was approved by University of Helsinki Viikki Campus Research Ethics Committee, Finland and Liverpool University Leahurst Campus Research Ethics Committee, UK and signed consent from the owner of the dogs was acquired.

The dogs were recruited from a husky farm in Lapland, Finland. Their back length was measured with a tape measure from the external occipital protuberance to the sacro-caudal junction. The height of the dogs was also measured with a tape measure from the ground to the dorsal borders of scapulae. In addition, they were weighed on the same bathroom scale.

The inclusion criteria for the dogs were: weight between 22 to $27 \mathrm{~kg}$, aged 2 to 8 years (common age range for working dogs (Von Pfeil et al., 2015)), and at least 3 months of experience in running in a team. All dogs had to also be free of any previous or current orthopaedic disorders as reported by the owner. All dogs were assessed by a licensed physiotherapist (FP). The exclusion criteria were: abnormal findings in physiotherapeutic neuromusculoskeletal examination, dogs that showed aggression in the team or biting at the lines.

All of the dogs had been previously trained with only traditional gang-lines. Dogs were put on two teams of 4 dogs, Team 1 (T1) and Team 2 (T2), in a placement order familiar to them, wearing their own harnesses fitted to their size (Table 1).

Table 1. Description of the teams of dogs (Team 1 and Team 2) showing the positions of the 8 dogs $(A-H){ }^{1}$

\begin{tabular}{l}
$\begin{array}{l}\text { Positions } \\
\begin{array}{l}\text { Team 1: } \\
\text { left side }\end{array}\end{array} \begin{array}{l}\text { Team 1: } \\
\text { right side }\end{array} \quad \begin{array}{l}\text { Team 2: } \\
\text { left side }\end{array}$ \\
$\begin{array}{l}\text { Front } \\
\text { Hind }\end{array}$ \\
\hline C
\end{tabular}

Each team ran the $3.1 \mathrm{~km}$ trail normally run by the dogs as part of their daily practice routine twice with both gang lines, with their usual trainer (musher). The trail was an oval shape forest trail, turning mostly to the left. On the video, the five curves lasted for $11 \mathrm{~s}$ (left), $25 \mathrm{~s}$ (left), $4 \mathrm{~s}$ (left), $23 \mathrm{~s}$ (left) and $5 \mathrm{~s}$ (right), summing up to $1 \mathrm{~min} 8 \mathrm{~s}$ for a single $7 \mathrm{~min} 35 \mathrm{~s}$ round. There were two inclines and two declines on the route. A traditional and a stick gang-line was used once with each team (Table 2).

The order of which line was used, was randomly assigned (by tossing a coin). A musher (79 kg wearing training clothes, $174 \mathrm{~cm}$ ) was seated on a quadbike without running motor (TMS TV 200 cc, 165 kg; Trend Motor Sports, Stockholm, Sweden) to run both teams on each of their runs. The same material and supplier were used for the traditional gang-line and the stick gang-line (Swisscool Mushing, Le Châtelard, Switzerland). The lines were composed of damper, polyethylene rope, carabiners plus a wooden stick for the stick gang-line. The same track was used for all the runs. All of the data was collected in $1 \mathrm{~h}$ $24 \mathrm{~min}$. over a single day during which the weather and temperature conditions were as similar as possible, in an attempt to control weather-related factors like friction and extreme changes in temperatures.

Reflective markers ( $\mathrm{Ra} 3$, white, $5 \mathrm{~cm}$ large, $15 \mathrm{~cm}$ along the line) were used: two were placed on the junction of the gang-line and the tug-lines, to observe the orientation of the dog compared to the gang-line (Figure 1A and 1B). Two 15 $\mathrm{cm}$ long colour marks (animal marking crayon, Raildl maxi, red, $3 \mathrm{~cm}$ large; Raidex $\mathrm{GmbH}$, Dettingen an der Erms, Germany) were painted on the back of each dog: caudal from the occiput and cranial from the sacro-caudal joint (Figure 1C). A video camera (Bullet 5S 1080p, 1280×720 px, 50F, 16:9; Rollei GmbH \& Co.KG, Hamburg, Germany) was attached to the musher's helmet. The musher also wore a GPS (Garmin Dakota 20 ${ }^{\oplus}$; Garmin Ltd., Olathe, KS, USA) to record the time of the runs and the mean speed of the dogs during the runs.

Table 2. Description of run sequence: order of the four runs of both teams, Team 1 and Team 2, in the stick and the traditional gang-lines. ${ }^{1}$

\begin{tabular}{lllll} 
Runs & $\mathbf{1}$ & $\mathbf{2}$ & $\mathbf{3}$ & $\mathbf{4}$ \\
Team 1/Team 2 & T1 & T2 & T1 & T2 \\
Trad/Stick & Stick & Trad & Trad & Stick \\
\hline${ }^{1}$ Trad = traditional gang-line; Stick = stick gang-line. &
\end{tabular}


Measurements were taken of the angle of pull for each dog from still pictures, taken from the recorded video at oneminute intervals. If needed, the moment of measurement was changed by the minimal amount needed backwards or forwards from that minute, to ensure clear view of the markers, ensuring the musher was positioned straight behind the team with no distractions and sufficient quality of picture, and that dogs were not on a turn when image was captured. Reasons for poor visibility included dogs' tail position blocking the view to a marker, or the musher momentarily jumping off from the quad. Moreover, no images were captured during the first $45 \mathrm{~s}$ of the runs, as dogs were still in the camp area, disturbed by other dogs on the premises.

From the pictures, the dogs' angle of pull in relation to the main-line was measured as degrees of angle between the line of dog's spinal markers and the line of the main-line markers, using appropriate software (Kinovea version 8.15; https://www.kinovea.org). When measuring the angles, a perspective correction was used (Figure 2). The angles were then used to calculate the differences in the dog's angle of pull in between the two line types.

The data was tested for normality using the ShapiroWilk test. The conformation related data was normally distributed. However, the pulling position related data, all dogs mean values pooled, for the stick gang-line was not normally distributed $(P<0.001)$, and only barely normally distributed for the positions in traditional gangline $(P=0.056)$. Also, as the number of dogs in this study was relatively small, non-parametric tests were used to analyse the angles of pull statistically. Comparison between groups as well as individual dog's angles of pull under both conditions was done with a non-parametric Wilcoxon signed rank test.

All dogs' mean pulling angles (per gang-line type as well as both gang-line angles pooled) were examined for correlations with the dogs' weight, age, back length and height. This was done non-parametrically, by using the Spearman's rho test.

All data was statistically analysed with SPSS (version 25.0; IBM, Armonk, NY, USA). The significance level for all tests was set to $P \leq 0.05$. Descriptive animal related results are presented as median and inter quartile range (IQR) except for the weather characteristics and speed of the runs which are presented as mean \pm standard deviation.
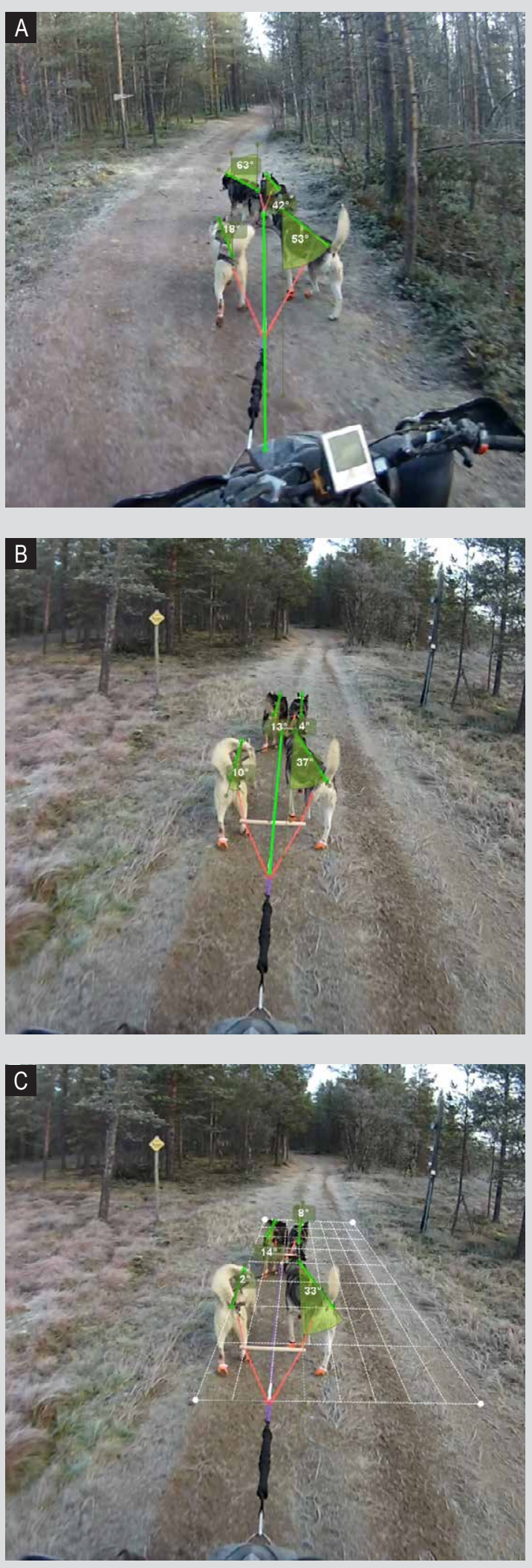

Figure 2. Examples of pulling positions' angle calculations using Kinovea software. (A) The traditional gang-line measurements; (B) stick gang-line measurements; (C) a view of the use of perspective correction. 


\section{Results}

\section{Animals}

Eight male Alaskan huskies, aged median 7 years (IQR 3 years 6 months) and weighing median 23.5 (IQR 3) kg were included in the study. The median length of the back of dogs was 83 (IQR 4) $\mathrm{cm}$ and the median wither height was 61.5 (IQR 4) cm (Table 3). Only one dog was castrated (dog A).

Data was collected on $24^{\text {th }}$ October 2018 , between 10:58 to $12: 22$. The day was sunny, with mean temperature of $-7.75 \pm 0.7^{\circ} \mathrm{C}$, range $-8^{\circ}$ to $-6^{\circ} \mathrm{C}$. The mean speed during all four runs was $16.04 \pm 2.45 \mathrm{~km} / \mathrm{h}$ ). The T2 was faster (mean speed of $17.36 \pm 11.12 \mathrm{~km} / \mathrm{h}$ ) than $\mathrm{T} 1$ (mean speed of $14.32 \pm 5.04 \mathrm{~km} / \mathrm{h}$ ) in both of their runs. The dogs' gaits in the still images where the dogs' pulling angle was measured from, are presented in Table 4.
The teams had a break of $29.5 \pm 1.5$ min between runs. Twenty-six angle of pull measurements per dog were collected, 13 per dog with the traditional gang-line, and 13 with the stick gang-line. This yielded as a total of 208 time point measurements.

\section{Traditional versus stick gang-line: all dogs assessed as a group}

When the two conditions were compared with all dogs positions pooled together, the angle of pull of the dogs was significantly straighter when running with the stick gang-line $(n=104)$, than when running with the traditional gang-line $(\mathrm{n}=104)(P<0.001)$, with a median of $19^{\circ}(\mathrm{IQR}$ $24.75^{\circ}$ ) and $32^{\circ}\left(\right.$ IQR $25.75^{\circ}$ ), respectively.

Table 3. Descriptive information of 8 dogs $(\mathrm{A}-\mathrm{H})$ while pulling a quadbike in a traditional (trad) and a stick gang-line over the same $3.1 \mathrm{~km}$ trail and the respective pulling angles. ${ }^{1,2}$

\begin{tabular}{|c|c|c|c|c|c|c|c|c|}
\hline Dogs & $\begin{array}{l}\text { Age (years, } \\
\text { months) }\end{array}$ & $\begin{array}{l}\text { Weight } \\
\text { (kg) }\end{array}$ & $\begin{array}{l}\text { Back length } \\
(\mathrm{cm})\end{array}$ & $\begin{array}{l}\text { Wither height } \\
\text { (cm) }\end{array}$ & $\begin{array}{l}\text { Head in/out } \\
\text { Stick/Trad }\end{array}$ & $\begin{array}{l}\text { Median stick } \\
\text { angle (IQR) }\end{array}$ & $\begin{array}{l}\text { Median trad } \\
\text { angle (IQR) }\end{array}$ & $\begin{array}{l}\text { Statistical significance of the } \\
\text { difference Stick/Trad }\end{array}$ \\
\hline A & 7 y $11 \mathrm{~m}$ & 23 & 83 & 61 & out/out & $43^{\circ}\left(21.5^{\circ}\right)$ & $53^{\circ}\left(19^{\circ}\right)$ & $P=0.046^{*}$ \\
\hline B & 7 y $8 \mathrm{~m}$ & 24 & 84 & 58 & in/in & $17^{\circ}\left(23.5^{\circ}\right)$ & $34^{\circ}\left(30^{\circ}\right)$ & $P=0.093$ \\
\hline C & 8 y $1 \mathrm{~m}$ & 26 & 83 & 60 & in/out & $11^{\circ}\left(11^{\circ}\right)$ & $23^{\circ}\left(17.5^{\circ}\right)$ & $P=0.003^{*}$ \\
\hline D & 8 y $1 \mathrm{~m}$ & 27 & 78 & 62 & in/in & $24^{\circ}\left(16^{\circ}\right)$ & $36^{\circ}\left(11.5^{\circ}\right)$ & $P=0.004^{*}$ \\
\hline$E$ & 6 y $4 \mathrm{~m}$ & 22 & 84 & 63 & out/out & $29^{\circ}\left(19.5^{\circ}\right)$ & $40^{\circ}\left(24^{\circ}\right)$ & $P=0.042^{*}$ \\
\hline $\mathrm{F}$ & 5 y $7 \mathrm{~m}$ & 23 & 83 & 62 & in/in & $13^{\circ}\left(15^{\circ}\right)$ & $36^{\circ}\left(10.5^{\circ}\right)$ & $P=0.003^{*}$ \\
\hline G & 2 y $5 \mathrm{~m}$ & 22 & 79 & 56 & out/out & $41^{\circ}\left(17.5^{\circ}\right)$ & $7^{\circ}\left(8.5^{\circ}\right)$ & $P=0.001^{*}$ \\
\hline $\mathrm{H}$ & 4 y $3 \mathrm{~m}$ & 24 & 81 & 66 & in/in & $10^{\circ}\left(11.5^{\circ}\right)$ & $19^{\circ}\left(13.5^{\circ}\right)$ & $P=0.021^{*}$ \\
\hline
\end{tabular}

Table 4. Gaits used by dogs in which the pulling position measurements were taken.

\begin{tabular}{|c|c|c|c|c|c|c|c|c|}
\hline \multirow[t]{2}{*}{ Dog } & \multirow{2}{*}{$\begin{array}{l}\text { Number of images used for } \\
\text { angle measurements }\end{array}$} & \multicolumn{3}{|c|}{ Traditional gang-line } & \multirow{2}{*}{$\begin{array}{l}\text { Number of images used for } \\
\text { angle measurements }\end{array}$} & \multicolumn{3}{|c|}{ Stick gang-line } \\
\hline & & Trot & Pace & Gallop & & Trot & Pace & Gallop \\
\hline A & 13 & 11 & 0 & 2 & 13 & 11 & 0 & 2 \\
\hline B & 13 & 13 & 0 & 0 & 13 & 13 & 0 & 0 \\
\hline C & 13 & 12 & 0 & 1 & 13 & 12 & 0 & 1 \\
\hline D & 13 & 13 & 0 & 0 & 13 & 13 & 0 & 0 \\
\hline$E$ & 13 & 12 & 0 & 1 & 13 & 11 & 0 & 2 \\
\hline$F$ & 13 & 6 & 0 & 7 & 13 & 5 & 0 & 8 \\
\hline G & 13 & 8 & 0 & 5 & 13 & 5 & 0 & 8 \\
\hline $\mathrm{H}$ & 13 & 0 & 9 & 4 & 13 & 0 & 11 & 2 \\
\hline
\end{tabular}




\section{Traditional versus stick gang-line: two teams assessed separately}

When teams were examined separately, T1 dogs (A, B, $\mathrm{C}, \mathrm{D})$ pulled significantly straighter in the stick gang line $(\mathrm{n}=52)\left(19^{\circ} ; \mathrm{IQR} 24.5^{\circ}\right)$ than in the traditional gang line $(\mathrm{n}=52)\left(34.5^{\circ}\right.$; IQR $\left.24.8^{\circ} ; P<0.001\right)$. For T2 (dogs E, F, G, $\mathrm{H})$, the difference between conditions was not statistically significant $(P=0.310)$, with median values $19^{\circ}\left(\mathrm{IQR} 25.8^{\circ}\right)$ for the stick gang-line $(\mathrm{n}=52)$, and $24^{\circ}\left(\mathrm{IQR} 27^{\circ}\right)$ for the traditional gang-line $(\mathrm{n}=52)$.

\section{Traditional versus stick gang-line: individual dog's assessments}

When the difference in the pulling angles between the two types of lines was assessed within each dog, as individuals, the angles of pull were significantly lower (straighter) in six of the eight $\operatorname{dogs}(P=0.003$ to 0.046$)$ when pulling using the stick gang-line $(\mathrm{n}=13)$ compared to the traditional gang-line $(\mathrm{n}=13)$, while a seventh dog showed a trend for a reduced angle $(P<0.1)$. However, one dog showed the reverse with significantly greater angle of pull when using the stick gangline $(P=0.001)$. The individual difference between the two gang-line conditions is described in Table 3. Variation in the angle of pull was seen within dogs as well as in between dogs.

None of the dogs ran exactly parallel to the main-line. There were 3 dogs running in under $20^{\circ}$ angle, 3 dogs running in 20-30 angle, and $1 \operatorname{dog}$ in $30-40^{\circ}$ and in 40-50 each, in the stick-line. In the traditional lines, 2 of the dogs run under $20^{\circ}$ angle, 1 dog in $20-30^{\circ}, 4$ dogs in $30-40^{\circ}$, and again 1 $\operatorname{dog}$ in $40-50^{\circ}$ angle. They ran diagonal either head out, and hind quarters in, or vice versa (Table 3). In all cases except one, the dog's direction of angle of pull remained the same despite the change of equipment. Three of the dogs ran head 'out', hindquarters 'in', in both conditions. These dogs were all placed on the left side of the team, as first and second. Four of the dogs run in an opposite angle of pull, head 'in' and hindquarters 'out', in both conditions. All of these dogs were placed on the right side of the team: as first and second. Dog $C$ who differed from this pattern, ran diagonally head on the inside, hindquarters on the outside with the stick lines, but when running with the traditional lines, he turned to the opposite angle of pull. This dog ran on the left of the main-line. Dog G had an opposite angle of pull compared to the others, and also an increased angle with stick rather than traditional gang-line. Dog H was mainly pacing instead of trotting (Table 4).

\section{Effect of the dog's placement on the team to the traditional versus stick gang-line}

When the effect of the placement in the team was further assessed, dogs running in front of both teams $(n=4: \operatorname{dogs} A$, $\mathrm{B}, \mathrm{E}$, and F) pulled significantly straighter when in the stick gang-line $\left(21^{\circ} ;\right.$ IQR 23.75$)$ than in the traditional gang-line (median $39^{\circ}$; IQR $\left.18 ; P<0.001\right)$. The dogs in the rear $(\mathrm{n}=4$ : $\operatorname{dogs} \mathrm{C}, \mathrm{D}, \mathrm{G}$, and $\mathrm{H}$ ) showed no significant differences between conditions; $17^{\circ}$; IQR 23.25 in the stick gang-lines and $21.5^{\circ}$; IQR 22 in traditional gang-lines $(P=0.301)$. In the stick-gang-line there was no statistically significant difference in the running positions of the front and hind $\operatorname{dogs}(P=0.473)$, whereas in the traditional gang-lines the front dogs ran in a significantly more angled position than the hind dogs $(P<0.001)$.

The difference in positions between the right and left side front and rear dogs was also assessed. The difference in running positions in front with the stick gang-line, between the left $(\mathrm{n}=4)$ (median $36^{\circ}$, IQR 23.25) and right side dogs $(\mathrm{n}=4)\left(15.5^{\circ}, \mathrm{IQR} 13.75^{\circ}\right)$ was significantly $(P<0.001)$ different, as it was also in the traditional gang-lines (left $46^{\circ}$, IQR 22.25 / right $35^{\circ} \mathrm{IQR} 16.25, P=0.002$ ). In the rear dogs, there was no statistically significant difference between the running positions of left (median $17.5^{\circ}, \mathrm{IQR} 38^{\circ}$ ) and right side dogs (median $17^{\circ}, \mathrm{IQR} 15.50^{\circ}$ ) in the stick gang-line $(P=0.096)$, but there was in the traditional gang-line (left $13^{\circ}$, IQR $22.50^{\circ} /$ right $31^{\circ}$, IQR $19, P<0.001$ ).

No statistically significant correlations were seen between any of the dogs' conformational factors or their age or weight and their angle of pull in either gang-line condition $(\mathrm{n}=8, P=0.061-0.810)$.

\section{Discussion}

Overall, when assessed as one group, dogs ran straighter when pulling using the stick gang-line than the traditional gang-line. The median $13^{\circ}$ difference between the ganglines equates to a $68 \%$ increase in pulling angle when the traditional gang-line is used instead of the stick one. This was despite there being more marked variation in the orientation and angle of pull between and within dogs than anticipated and used in the power calculations. Individually, most of the eight dogs, had a straighter pulling position (lower angle) with the stick gang-line than with the traditional gang-line. With the stick gang-line, 6 dogs (75\%) ran at less than a $30^{\circ}$ angle, whereas with the traditional gang-line, only $3(37.5 \%)$ did the same.

Some dogs (dog A in T1, dog D in T1, dog E in T2) were observed pulling in a wide, over $60^{\circ}$ of an angle especially in the traditional gang-line, moving almost side first like 'a crab'. Anecdotally, this type of pulling position is often seen. Although the reason for such position is unknown to 
us, and although the position recorded in these dogs differs from others, it still relates to true clinical and functional position and is a true result, and as such it is a part of normal variation in pulling positions, and a reason why we did not exclude them. It might be that the dog has a subclinical orthopaedic issue that we are were unable to detect in clinical examination, or that this was a learned motor behaviour. Nevertheless, each of these dogs pulled straighter in the stick gang-line despite their crablike position.

When assessed by placement in the team, the four dogs in front, leading, had straighter pulling angles when running using the stick gang-lines, while the rear four dogs showed no difference between the two line types, when assessed as a group. But when side was taken into account, the right side dogs were running more in angle in traditional gang-line than in stick gang-line. The position of the leading dogs may have been influenced by the trail, which contained turns mostly to the left side. The dogs may anticipate the turns, which may explain why all the dogs were positioned diagonally to the left, i.e. dogs on the left of the gangline had that preferences to have the head 'out', and the dogs on the right had a preference to have the head 'in'. This observation doesn't change the importance of the differences in the angle between the two types of gang-lines, as the placement of the dogs in their teams was same on each run. The maximum angles of the dogs in front and hind were to opposite directions, which may indicate factors other than turns affect hind dog angles of pull.

It is reported that the rear dogs use more force than front dogs to pull (LaBelle, 2007a) and it could be that the increased load on the rear dogs may be influencing their angle of pull. In this study, dogs in the rear were straighter with both gang-lines. This might support the speculation that a straighter angle of pull helps force production. During our data collection, each dog stayed in their own, familiar place in the team throughout all runs, and did not change places. Running in one place in a team may lead to dogs having individual positioning strategies. Had the places been changed, dogs might have behaved differently in placements unfamiliar to them. As each dog served as their own control between the two conditions (traditional and stick gang-line), it was decided to keep them in a place familiar to them in all runs, to avoid changes related to other factors than the equipment. Further research to measure the force of each dog in a team to confirm if the position and angle influence force production is warranted.

It is not known if a greater angle of pull compared to the straighter, more parallel angle of pull is more or less biomechanically efficient. Similarly, it is not known if a straighter pull results in reduced or more evenly distributed forces on the harness or not. As dogs' limbs are biomechanically designed to work mainly in sagittal plane (Fischer et al., 2014), it could be assumed, that a straighter pulling angle would be more optimal in injury prevention sense. It could be speculated that back torsions might also lead to back dysfunction and musculoskeletal strain (Orantes-Gonzalez and Heredia-Jimenez, 2017; Ortega et al., 2014; Von Pfeil et al., 2015). However, none of this was assessed in our study, and further studies are needed to define the specific strains on the musculoskeletal system due to various working angle of pull under load. The knowledge gained from this study may be used as a basis for further research on the force production and distribution in harnesses at different angles with the aim of determining the most optimal pulling angle to minimise risk of musculoskeletal injury or fatigue.

The Alaskan husky is an unofficial breed, resulting of selective breeding strategies related to performance (Brown et al., 2015; Huson et al., 2010). The dog's type may change depending on the geographic location, the lineage and the racing style (sprint vs endurance) (Huson et al., 2010, 2012). In our study, we studied Alaskan Huskies both bred and trained in distance running. This type of sled dog is most commonly used for competing purposes (Lee, 2015; Yukon Quest, 2018b). Only males were used, not only for homogenisation of our study group, but also for practical reasons. In the farm where the data collection was done, most of the dogs are entire, so two sexes are not mixed in teams. Moreover, the owner of the dogs considered the females to be too weak to pull the quadbike in a four dog team.

We did not find any correlation between conformation and the pulling angle in the dogs in our study. Nevertheless, due to our small sample size and small differences in the conformational variables in these dogs (for example less than $3 \mathrm{~cm}$ difference in six of the dogs' back length, clinically not significant), no conclusions or generalisations regarding the effect of conformation to the pulling angle of a sled dogs should be made based on our data. Research on trotting dogs from different breeds led the authors to propose than shorter back mammals are more prone to sideway trotting to avoid touching the forelimbs with the hindlimbs (Hildebrand, 1968). This is in line with the descriptive data of our study. Further studies are warranted, but the addition of angles in different planes may increase the difficulty to pull (Coppinger et al., 1998), as with the traditional gangline, which increases the angle of pull in comparison to the stick gang-line, which in turn decreases the sagittal angle of traction. The effect of the conformational related factors' can only be speculated, and further studies on them and their effect on pulling angle and different equipment with larger numbers are needed.

Further, when looking at individual dogs, other factors may have been involved, like fatigue and lack of experience 
in the youngest of dogs, galloping more than most of the other dogs. Although the effect of experience has not been studied in this sense previously, it has been reported that in agility, experienced dogs are less prone to injuries than younger dogs, and younger sled dogs are more prone to being disqualified for health reasons from races than older ones (Helton et al., 2007; Von Pfeil et al., 2015).

The markers and videotaping have been used in previous studies relating to kinematic gait analysis (Foss et al., 2013; Gomez Alvarez et al., 2017; Grabowski and Kram, 2008; Hicks and Millis, 2014; Lorke et al., 2017) and found to be reliable methods of measuring dogs' movement (Foss et al., 2013; Gomez Alvarez et al., 2017; Lorke et al., 2017). Although the cameras have been fixed in most of the previously published dog studies, in several studies related to horses' kinematics the camera have been attached to for example a vehicle following the horse (Holden-Douilly et al., 2013). In a previous study, reflective markers were glued to the skin on bony landmarks of the limbs on Labrador retrievers. Between standing and walking, the skin has a displacement relative to the bony landmarks from 0.4 to $1.2 \mathrm{~cm}$ (Schwencke et al., 2012). In our study, the dogs' hair was too thick to just glue the markers on them. Clipping of the hair for this purpose was not possible due to the time of the year for these working dogs. We also decided not to use the option of wearing a T-shirt with the markers glued on it, as in pilot testing large displacements of the markers was observed due to the shirt rolling on the dog's hair. In addition, with the movement of the running dogs and the harnesses close to the marked areas, tape or glue attached markers were found to have insufficient attachment ability, and markers would be lost. In our study, we decided to colour mark the hair according to above described protocol on standing position. On some still images retrieved from the video, and on some dark coloured dogs the markings were somewhat difficult to see, but based on the clearly visible anatomy of the dogs, the pulling angles could be verified from the occiput, i.e. between the ears, and the saccrocaudal junction, i.e. the base of the tail.

The data collection for this study was done on dry land on late autumn for several reasons. Firstly, to get a better view on the backs of the dogs, the camera can record a higher view of the dogs from a quadbike than from a sled, as the musher is placed higher on the quadbike. Secondly, on dry land, we have less friction related variables than on snow, where the melting during the day might cause a problem. Thirdly, to video record the runs, daylight is necessary. We were able to control the weather-related factors as well as possible, to ensure a comfortable temperature for the dogs and to avoid hyperthermia. Especially dark-coloured male dogs that are at risk, with increasing running speed, of a potentially fatal heatstroke (Carter and Hall, 2018). Additionally, during wintertime, cold weather would be a problem for battery life, and therefore for use of cameras and GPS systems.

The transferability of the results of our study performed on dry land, with a quadbike to a situation where the dog runs on snow in front of the sled is not necessarily straight forward. The attachment to the sled may be lower than on quadbike, which may change the angle of traction, thus affecting the force needed to pull (Coppinger et al., 1998). With a lower attachment, the force required to pull increases and pull even more down the back of taller dogs, especially those nearest to the sled, closer to this attachment of the main line (Von Pfeil et al., 2015).

A limitation in our study was lack of acclimatisation. All dogs participating in this study were used to run in traditional gang-line but not in stick gang-line, and no acclimatisation to the latter was made. Nevertheless, the position of dogs was immediately straighter in stick-lines, and if the above discussed assumption that straighter pulling position is better for the dogs is true, then such impact even without acclimatisation is suggestive of clinically significant effect.

Another factor to consider, were the gaits which were accepted to our analysis. Despite running in teams, individual dogs in those teams may use various gaits depending of their conformation in relation to other dogs and velocity, their physical fitness and fatigue level, and the terrain. As mixed gaits may be presented in a team during a run, and as we were approaching the pulling positions from a cross over design point of view, we decided not to exclude any gaits, but to analyse dogs pulling positions during which ever gait the dogs were using at the time of the image capture. Thus, all still images with trotting, pacing and galloping gaits in them were accepted for analysis. In all 26 images of four of the eight dogs, there were exactly the same amount of trot and gallop images in between the traditional and the stick gang-line. In two dogs there were $7.7 \%$, and in one $\operatorname{dog} 23 \%$ more gallop than trot images in stick gang-line, and in one dog there was $15.4 \%$ more gallop than pace images in stick gang-lines. These differences in used gaits within a dog and within a group were considered representative of the real-life situation. It is noteworthy, that albeit the footfall pattern of the gallop (an asymmetrical gait) and trot (a symmetrical gait) do differ, the pulling angle of the dog should not be affected by the gait especially in steady state, which is what was recorded in this study.

\section{Conclusions}

Pulling position was straighter with the stick gang-line for most sled dogs pulling a quadbike on dry land in teams of four dogs, especially those in the front half of the team, in comparison to the pulling position with the traditional gang-line. With dogs always trained with traditional gang- 
line, the improvement of straighter pulling angle with the stick gang-line is immediate.

\section{Acknowledgements}

The authors would like to acknowledge the Hetta Huskies for their contribution as well as the dogs that participated in the pilot.

\section{Conflict of interest}

Authors declare no conflict of interests. The study received no funding.

\section{References}

Brown, S.K., Darwent, C.W., Wictum, E.J. and Sacks, B.N., 2015. Using multiple markers to elucidate the ancient, historical and modern relationships among North American artic dog breeds. Heredity 115: 488-495. https://doi.org/10.1038/hdy.2015.49

Carter, A.J. and Hall, E.J., 2018. Investigating factors affecting the body temperature of dogs competing in cross country (canicross) races in the UK. Journal of Thermal Biology 72: 33-38. https://doi. org/10.1016/j.jtherbio.2017.12.006

Coppinger, R., Coppinger, L. and Skillings, E., 1998. Observations on assistance dog training and use. Journal of Applied Animal Welfare Science 1: 133-144. https://doi.org/10.1207/s15327604jaws0102_4

Femundlopet, 2018. The track 2019. Femundlopet, Røros, Norway. Available at: https://femundlopet.no/en/the-track/

Finnmarkslopet, 2018. The trail. Finnmarkslopet, Alta, Norway. Available at: http://www.finnmarkslopet.no/home-trail/

Fischer, M.S. and Lilje, K.E., 2014. Muscles. In: Fischer, M.S. and Lilje, K.E. (eds.) Dogs in motion, $2^{\text {nd }}$ edition. VDH Service GmbH, Dortmund, Germany, pp. 98-129.

Foss, K., Da Costa, R.C. and Moore, S., 2013. Three-dimensional kinematic gait analysis of Doberman pinschers with and without cervical spondylomyelopathy. Journal of Veterinary Internal Medicine 27: 112-119. https://doi.org/10.1111/jvim.12012

Gomez Alvarez, C.B., Gustas, P., Bergh, A. and Rhodin, M., 2017. Vertical head and pelvic movement symmetry at the trot in dogs with induced supporting limb lameness. The Veterinary Journal 229: 13-18. https://doi.org/10.1016/j.tvjl.2017.10.011

Grabowski, A.M. and Kram, R., 2008. Running with horizontal pulling forces: the benefits of towing. European Journal of Applied Physiology 104: 473-479. https://doi.org/10.1007/s00421-008-0785-8

Grandjean, D., 1989. Entraînement ou course: le matériel nécessaire. In: Grandjean, D. (ed.) Les chiens de traîneaux: de la peur du loup à l'amour d'un chien, $1^{\text {st }}$ edition. Editions Amphora s.a., Paris, France, pp. 55-80.

Gysin, P., Kaminski, T.R., Hass, C.J., Grobet, C.E. and Gordon, A., 2008. Effects of gait variations on grip force coordination during object transport. Journal of Neurophysiology 100: 2477-2485. https://doi. org/10.1152/jn.90561.2008

Helton, W.S., 2007. Skill in expert dogs. Journal of Experimental and Psychologial Applications 13: 171-178. https://doi.org/10.1037/1076898X.13.3.171
Hetta Huskies, 2018. Husky safaris. Hetta Huskies, Enontekiö, Finland. Available at: http://www.hettahuskies.com/en/activities/multiday-husky-safaris

Hicks, D.A. and Millis, D.L., 2014. Kinetic and kinematic evaluation of compensatory movements of the head, pelvis and thoracolumbar spine associated with asymmetric weigth bearing of the pelvic limbs in trotting dogs. Veterinary Comparative Orthopaedics and Traumatology 27: 453-460. https://doi.org/10.3415/VCOT-1404-0057

Hildebrand, M., 1968. Symmetrical gaits of dogs in relation to body build. Journal of Morphology 124: 353-360. https://doi.org/10.1002/ jmor.1051240308

Holden-Douilly, L., Pourcelot, P., Desquillbet, L., Falala, S., CrevierDenoix, N. and Chateau, H., 2013. Equine hoof slip distance during trot at training speed: comparison between kinematic and accelerometric measurement techniques. The Veterinary Journal 197: 198-204. https://doi.org/10.1016/j.tvjl.2013.02.004

Huson, H.J., Parker, H.G., Runstadler, J. and Ostrander, E.A., 2010. A genetic dissection of the breed composition and performance enhancement in the Alaskan sled dog. BMC Genetics 11: 1-14. https://doi.org/10.1186/1471-2156-11-71

Huson, H.J., VonHoldt, B.M., Rimbault, M., Byers, A.M., Runstadler, J.A., Parker, H.G. and Ostrander, E.A., 2012. Breed-specific ancestry studies and genome-wide association analysis highlight an association between the MYH9 gene and heat tolerance in Alaskan spring racing sled dogs. Mammalian Genome 23: 178-94. https:// doi.org/10.1007/s00335-011-9374-y

Iditarod, 2018. Race map. Available at: https://iditarod.com/race-map/ LaBelle, C.G., 2007a. Team members. Mush! Revised: a beginner's manual of sled dog training, $4^{\text {th }}$ edition. Barkleigh Productions, Mechanicsburg, PA, USA, pp. 6-7.

LaBelle, C.G., 2007b. Lines. Mush! Revised: a beginner's manual of sled dog training, $4^{\text {th }}$ edition. Barkleigh Productions, Mechanicsburg, PA, USA, pp. 46-51.

Lee, J.J., 2015. What makes a great sled dog? Breed, ambition, tough feet. National Geographic, Boone, IA, USA. Available at: https:// tinyurl.com/y2ut4nmn

Lorke, M., Willen, M., Lucas, K., Beyerbach, M., Wefstaedt, P., Escobar, H.M. and Nolte, I., 2017. Comparative kinematic gait analysis in young and old beagle dogs. Journal of Veterinary Science 18: 521530. https://doi.org/10.4142/jvs.2017.18.4.521

Orantes-Gonzalez, E. and Heredia-Jimenez, J., 2017. Pulling a school trolley: a good kinematic option for children. Gait and Posture 53: 61-66. https://doi.org/10.1016/j.gaitpost.2017.01.012

Ortega, F.Z., Sanchez, M.F., Garcia, R.F., Schyke, C.E.J. and Morales, L.Z., 2014. Predictors of scoliosis in school-aged children. Gaceta Medica de Mexico 150: 524-530.

Peham, C., Limbeck, S., Galla, K. and Bockstahler, B., 2013. Pressure distribution under three different types of harnesses used for guide dogs. The Veterinary Journal 198: e93-98. https://doi.org/10.1016/j. tvjl.2013.09.040

Schwencke, M., Smolders, L.A., Bergknut, N., Gustas, P., Meij, B.P. and Hazewinkel, H.A., 2012. Soft tissue artifact in canine kinematic gait analysis. Veterinary Surgery 41: 829-837. https://doi.org/10.1111/ j.1532-950X.2012.01021.x 


\section{F. Pittet et al.}

Von Pfeil, D.J.F., Liska, W.D., Nelson, S., Mann, S. and Wakshlag, J.J., 2015. A survey on orthopedic injuries during a marathon sled dog race. Veterinary Medicine 6: 329-339. https://doi.org/10.2147/ VMRR.S88276

Wilderness Tour, 2018. Akaskero. Available at: https://akaskero.com/ en/schlittenhundezentrum/wildnistour/
Yukon Quest, 2018a. Yukon quest distance chart. Available at: https:// www.yukonquest.com/fr/node/374

Yukon Quest, 2018b. The modern sled dog. Available at: http://www. yukonquest.com/about/sled-dogs/modern-sled-dog 